Изместьев Сергей Владимирович

независимый исследователь, практикующий юрист,

член Ассоциации юристов стран

Черноморско-Каспийского региона

\section{ГЛОБАЛЬНАЯ РЕВОЛЮЦИЯ И «РИТУАЛЬНОЕ» ГОСУДАРСТВО}

Аннотация:

В статье рассматривается влияние процессов глобализации на общество и государство. Автором выделяются два сложившихся типа глобализации: объединения государств и объединения людей на основе глобальных информационно-комму никационных технологий, демонстрируется взаимосвязь между развитием информационного обмена и демократизацией, дебюрократизацией общества. Отдельно анализируются проблемы проявлений фундаментализма, изоляционизма и противодействия процессам народной глобализации заинтересованными группами с использованием коллективных и медиаритуалов, ограничения прав граждан на свободу обмена информацией, доступа к сети Интернет на государственном уровне. Описывается феномен противодействующего глоба лизации на общественном уровне постмодернистского "ритуального» государства, попытки моно полизации им информационной и духовной сфер, ответное объединение усилий общества - глобальная революция. В связи с этим предлагаются расиирение международно-правовых гарантий на участие личности в обмене информацией и свободный доступ к средствам такого обмена как естественных прав человека, международно-правовая регламентация статуса и деятельности глобальных объединений, создание гарантий для участников глобального информационного обмена

Ключевые слова:

глобализация, глобальная революция, свобода Интернета, право на Интернет, наднациональные объединения, "ритуальное» государство, ритуальное право, ритуализация, фундаментализм, бюрократия.
Izmestyev Sergey Vladimirovich

Independent Researcher, Practicing Lawyer, Member of the Association of Lawyers

in the Countries

of The Black Sea-Caspian Region

\section{GLOBAL REVOLUTION AND "RITUALISTIC STATE"}

of obalization processes on society and state. The author emphasizes two emergent types of globalization, such as unification of states and unification of people based on global information and communication technologies and demonstrates the relationship between the development of information exchange and democratization, de-bureaucratization of society. The paper analyzes the problems of fundamentalism, the isolationism, and the resistance to the processes of the people globalization by affected groups us ing collective and media rituals, restriction of citizens" rights to freedom of information exchange, and access to the Internet at the state level. The author describes a phenomenon of a post-modern "ritualistic" state (or a ceremonial state) that resists the globalization processes at a societal level and attempts to monopolize the information and the spiritual spheres, and the resulting people unification, so-called "the global revolution". In that respect, it is proposed to extend the international legal guarantees for participation in the exchange of information and free access to means of such exchange as natural human rights, as well as the international legal regulation of the status and activities of global associations, and creation of guarantees for the participants of the global information exchange.

Keywords: globalization, global revolution, freedom of the Internet, supranational associations, "ritualistic" state, ritualistic law, ritualization, fundamentalism, bureaucracy.

В современном мире все становится глобальным: мировая ффинансовая система, мировая торговля, наука, культура, всемирное здравоохранение, планетарный климат и даже организованная преступность. Для решения глобальных задач нужен глобальный инструментарий. Отдельные национальные государства не способны эффективно решить их самостоятельно.

Глобализация - объективный процесс человеческой истории, знаменующий постепенное слияние семей в племена, племен - в народы, народов - в нации и цивилизации, с неизбежной утратой самобытных традиций, верований, языков и культур. Само понятие глобализации справедливо рассматривать не как отдельное явление, а как осознание обществом естественного процесса диалектического развития человечества в его исторической перспективе. Отрицание данного факта - сознательное искажение сути истории, отрицание собственно прогресса.

Интуитивно человечество постепенно объединяет усилия, формируя системы глобальной безопасности и глобального развития, которые должны поглотить часть государственных полномочий, «впитать» суверенитет государств в отдельных отраслях. Это приведет к неизбежному «концу международной политики» и формированию мировых органов безопасности, правосудия и развития.

Развитие информационного обмена, социальных сетей предоставляет эффективный механизм глобализации на личностном уровне - народную дипломатию - открытый диалог и обмен 
информацией между простыми людьми из разных концов мира. Свобода такого взаимодействия должна гарантироваться и защищаться международным сообществом от нападок и ограничений «ревнителей» и «жрецов» государственной монополии на управление обществом в любой точке мира.

Ранее нами было предложено выделить два исторически сложившихся типа глобализации в сфрере управления обществом: глобализацию наций и народную глобализацию. «Первый тип характеризуется объединением национальных государств в глобальные международные объединения, скрепляемые международным правом. Именно этот тип <«интернациональный»> можно справедливо назвать союзом неравных, где более крупные игроки "цивилизованного мира" зачастую решают задачи за счет более слабых партнеров, навязывая им свою политическую и экономическую волю. <...> Волей политиков, движущих данные процессы, такая глобализация зачастую вырождается в средство экспансии отдельных ее участников.

В последние десятилетия, благодаря развитию информационно-коммуникационных технологий, формируемому ими единому социокультурному пространству, можно говорить об ином типе глобализации в сфере управления обществом - народной, массовом стремлении людей мира к снятию барьеров для культурного и экономического взаимодействия» [1].

Этот процесс роста самосознания народных масс по всему миру за счет свободного обмена информацией, координации совместных действий и усилий в сфере защиты прав и свобод человека, борьбы за сохранение и создание благоприятной экологической и социальной среды смело можно назвать глобальной революцией. Яркими доказательствами этого служит появление всемирных народных движений активистов в сфере защиты экологии и прав человека, таких как экологическое движение сторонников Греты Тунберг за спасение климата Земли и международное правозащитное движение Black Lives Matter (BLM). Однако как на национальном, так и на международном уровнях отсутствуют законодательные основы статуса и гарантий деятельности таких объединений, их участников. Это создает предпосылки как для ущемления прав их участников отдельными государствами, так и для злоупотреблений самими объединениями.

Появление глобальных «социальных движений, превосходящих уровень местной или национальный политики» без участия существующих международных организаций было предсказано британскими социологами Э. Гидденсом и Ф. Саттоном в работе «Основные понятия в социологии» в 2018 г. [2, с. 17-18].

Наиболее успешным примером наднациональной глобализации сегодня является европейский опыт делегирования части государственного суверенитета на наднациональный уровень и перехода к единому европейскому постполитическому обществу. В рамках Европейского союза найден необходимый баланс между трансформирующимся институтом государства и формирующейся глобализованной общностью, который открывает перспективы как расширения сфреры глобализации, так и возможности включения в данный процесс новых и новых народов и территорий. При этом каждый новый участник получает больше готовых механизмов наднационального взаимодействия и транснационального управления, уже отлаженных и оформленных законодательно.

Отдельного исследования заслуживают обратные процессы, характерные для обществ и государств, скептически настроенных по отношению к участию в процессах мировой глобализации. Действующие общественные институты в таких обществах и государствах также подвержены трансформации, а органы власти неизбежно утрачивают реальные механизмы регулирования в глобализуемых сферах общественной жизни, прежде всего в фринансах, экономике, культуре и информационном обмене.

Современные исследователи отмечают взаимосвязь между уровнем демократии, развития общественных институтов и способностью общества к выходу на уровень наднационального взаимодействия. Чем выше уровень демократии и развития гражданского общества, тем более активно оно включается в формирование наднациональных структур.

Социологи свидетельствуют, что «распространению демократии в последнее время сильно способствовало развитие глобальных коммуникаций», а «права на участие в демократическом процессе сочетаются с гражданскими свободами - свободой самовыражения и дискуссии» $[3$, с. 82].

Таким образом, можно говорить о взаимосвязи процессов глобализации и демократизации общества, взаимоусиливающихся на протяжении всего XX столетия и начала нашего века, охвативших большую часть мира. Расширяющаяся под влиянием прогресса международная информационно-коммуникационная среда предоставляет людям из разных стран и обществ глобальную дискуссионную площадку, предназначенную для взаимообмена информацией об отдаленных и близких событиях, выражения мнения о них. Данная среда, слабо регламентированная национальным и международным правом, проявила способность к саморегулированию. Самым подходящим 
«уравнением» такого плюралистического диалога стали принципы равенства, взаимоуважения, корректности и терпимости, без которых невозможен плодотворный конструктивный диалог.

Следовательно, информационно-коммуникационная среда породила дискуссию, а дискуссия - демократию, которую, собственно, можно определить как равноправный общественный диалог. По словам Э. Гидденса, «наличие глобального информационного общества представляет собой мощную демократизирующую силу» [4, с. 92].

Благодаря развитию электронной коммуникации и демократизации этой коммуникационной среды государства и финансовые группы постепенно утрачивают право на информационную монополию в условиях глобального открытого обмена информацией. Это объясняется тем, что «авторитарное правление больше не соответствует новым условиям жизни, в том числе гибкости и динамизму, необходимым для конкурентоспособности в рамках глобальной электронной экономики. В мире, основанном на активном обмене информацией, жесткая власть теряет свою силу» [5, с. 86].

Однако информационные технологии могут быть использованы и широко применяются в пропагандистских целях. Это относится прежде всего к авторитетным международным и государственным СМИ, обеспечивающим одностороннюю трансляцию информации неограниченному кругу пользователей. Будучи подконтрольными государственным или частным влиятельным структурам, они служат распространению односторонней официальной тенденциозной оценки событий, без возможности их общественного обсуждения и диалога. Так, словами Э. Гидденса, «телевидение и другие СМИ уничтожают само публичное пространство для диалога» [6, с. 92]. Эта проблема стоит особо остро в обществе, где свобода слова не обеспечена законами и не контролируется общественными институтами. Существуют также примеры, когда благодаря глобализации мирового информационного пространства авторитетные международные СМИ, особенно новостные теле- и радиоканалы, интернет-гиганты служат инструментом политического и экономического давления в рамках межнациональной, межгосударственной политической и экономической конкуренции, обслуживают интересы крупных держав или транснациональных корпораций. Данное обстоятельство часто используется как повод для обоснованной критики процессов глобализации информационного пространства.

Таким образом, можно выделить два направления глобализации в информационном секторе: расширение сореры влияния крупных компаний и СМИ и развитие международных дискуссионных площадок на базе социальных сетей и сервисов в сети Интернет. Если первый тип не способствует совершенствованию гражданского общества и формированию наднационального постполитического мира, часто служит целям международного давления, протекционизма, незаконной слежки и вмешательства, то второй тип выступает инструментом народной глобализации путем включения людей в свободный равноправный диалог, выражением народной дипломатии без предрассудков и границ.

В связи с этим как никогда насущной является задача законодательно гарантировать на международном уровне естественное право людей на свободное участие в глобальном диалоге и обмене информацией посредством электронных сервисов и технологий. В отсутствие таких международно-правовых норм некоторыми государствами принимаются законодательные акты, направленные на ущемление прав человека в области свободного информационного обмена и доступа к сервисам и технологиям. Надо признать, что зачастую такие усилия нельзя назвать успешными в силу неподконтрольности данной глобализованной сферы отдельным государствам.

Передовым можно считать законодательство Финляндии, согласно которому каждому гражданину с июля 2010 г. гарантируется скоростное подключение к сети Интернет. Такое подключение в силу закона отнесено не к возможностям, а к правам гражданина Финляндии. Согласно опросам, четыре из пяти человек во всем мире сегодня считают, что доступ к Мировой паутине является фундаментальным правом [7].

Видится возможной и актуальной постановка вопроса о дополнении Европейской конвенции о защите прав человека и основных свобод положениями о гарантиях естественного права человека на свободный доступ к Интернету и обмен информацией в данной сети. Более того, защита информационных прав и свобод человека на доступ в Интернет и свободное пользование им заслуживает отдельных международных актов на уровне ЕС. Докладом Генеральной Ассамблеи ООН от 16 мая 2011 г. № A/HRC/17/27 «право на доступ в Интернет признается неотъемлемым правом человека. Таким образом, намеренное лишение людей в различных регионах мира возможности выйти в сеть Интернет отныне является нарушением прав человека» [8]. В докладе также говорится о том, что «Интернет имеет значительный потенциал и множество преимуществ, которые заключаются в том, что информация между пользователями распространяется с высокой скоростью, являясь при этом общедоступной, что вызывает страх многих правительств. Интернет является одним из способов объединения людей и борьбы за справедливость, считают 
авторы документа. Также подчеркивается, что обеспечение населения доступом в Интернет должно являться одним из приоритетных направлений развития любого государства» [9].

Среди различных возрастных групп по всему миру с каждым годом увеличивается число людей, использующих Интернет для свободного обмена информацией. Так, по данным агентства GfK, в России (стране со средними мировыми показателями информатизации) в 2019 г. в категории 65 лет и старше количество пользователей сети составило $36 \%, 50-64$ - 66, 40-49 - до 89, 30-39 - до 94, в категории 20-29 лет этот показатель находится на уровне 97 \%, а среди подростков (16-19 лет) проникновение Интернета достигло 100 \% [10]. Таким образом, в ближайшее время по мере смены поколений свободный доступ к сети станет неотъемлемой частью жизни каждого жителя планеты.

Исходя из высказанной Генеральной Ассамблеей ООН позиции, попытки отдельных политиков или национальных правительств ограничить свободный демократический диалог в сети Интернет должны рассматриваться как покушение на права человека, гражданского общества и собственно - демократию. Полагаем, что в этих случаях можно вести речь о противодействии глобализации, право на участие в которой должно быть признано естественным и неотъемлемым правом личности и также требует международной правовой защиты. Поскольку глобализация связана с развитием технологий, то противодействие этому процессу неизбежно является «кражей будущего», вынуждающей последующие поколения ускоренно догонять упущенное.

Ежегодно неправительственная организация Freedom House публикует результаты исследования Freedom on the Net, посвященного свободе Интернета в разных государствах мира. Данной организацией используется градация по степени свободы доступа к сети на страны свободного Интернета, относительно свободного Интернета, несвободного Интернета. В отчете за 2019 г. эксперты выразили обеспокоенность действиями правительств ряда стран, которые все чаще стали использовать Мировую паутину и социальные сети для того, чтобы следить за своими гражданами, контролировать их онлайновое поведение и манипулировать результатами выборов. Среди типичных нарушений свободы Freedom House назвала следующие:

- препятствия для доступа (Obstacles to Access) - инфрраструктурные и экономические барьеры для доступа к Интернету, государственный контроль над операторами связи, провайдерами, органами саморегулирования Интернета и пр.;

- ограничения распространения контента (Limits on Content) - законодательное регулирование интернет-контента, системы фильтрации и блокировки, механизмы самоцензуры, ограничение разнообразия средств массовой информации в сети и использования цифрровых инструментов для гражданской активности;

- нарушения прав пользователей (Violations of User Rights) - массовая слежка, нарушения конфиденциальности и преследование пользователей за выраженные в Интернете мнения (тюремное заключение, насилие в отношении блогеров, кибератаки и пр.) [11].

Строительство открытого информационного общества, как и глобализация, - это не вариант возможного развития, а осознание вектора многовекового движения человечества, осознание обществом реальности, требующее своевременной правовой регламентации. В то время как изоляционизм - продукт мифотворчества, уход от объективной реальности как таковой.

Под изоляционизмом (от фpp. isolation - отделение, разобщение) понимается «тип политического поведения, направленный на ограничение связей и отношений с другими субъектами» [12]. В фрокусе процессов глобализации причинами изоляционизма на национальном уровне могут выступать как желание политической или экономической элиты законсервировать существующую в стране модель, сохранить влияние или рынки, так и намеренное сдерживание крупными игроками потенциальных сильных игроков путем их принудительной политической либо экономической изоляции. Интерес к вынужденной изоляции национальных рынков может быть продиктован желанием заинтересованных групп сохранить искусственные непрозрачные, "теневые" зоны для получения или размещения нелегальных доходов.

Это еще один минус глобализации в интернациональном фоормате, которого лишены массовая народная глобализация и порождаемая ею глобальная революция. Предпосылками и признаками позитивной народной глобализации можно назвать свободный информационный обмен, равный открытый диалог, развитие гражданского общества, рост демократии, взаимотерпимости, укрепление мира и взаимопонимания между народами.

В современных условиях молодежь справедливо рассматривает традиционную политику как корыстную деятельность самих политиков. Классический парламентаризм, представительная демократия более недостаточны для учета мнений граждан, нужна прямая электронная демократия, учитывающая интересы «заинтересованных групп» избирателей. Такая практика станет подлинным возрождением общинного духа, продолжением традиций народных сходов и советов на новом витке развития человечества, знаменующим возврат власти от элит к самому обществу. 
Не вызывает сомнения, что «в детрадиционализирующемся мире политики для оправдания своей деятельности уже не могут полагаться на прежние формы - помпезные и торжественные церемонии» [13, с. 87]. Однако со стороны правящих кланов, политических элит в отдельных государствах можно наблюдать усиление организованного противодействия осознанию обществом нарастающих процессов глобализации. Речь идет именно о сознательной подмене повестки, мистификации, реально не противостоящей процессу глобализации, а лишь направленной на отвлечение от него общественного сознания.

Возникает феномен «ритуального» государства, в котором утрачиваемые в связи с выходом из-под государственного контроля отдельных сфрер жизни общества регуляторные полномочия в них замещаются демонстративной деятельностью госаппарата, носящей показной, ритуальный характер. При этом необходимость существования тех или иных властных структур обосновывается необходимостью совершения ими таких «ритуалов и церемоний».

Нежелание политических структур включаться в процесс глобального взаимодействия на наднациональном уровне, очевидная слабость и недееспособность политической системы подаются обществу как результат внешних заговоров и угроз. Это выражается в идеологии фундаментализма, который метко определен Э. Гидденсом как «традиции в осаде» или «традиции, которые отстаиваются традиционным способом - ссылками на ритуальную истину - в условиях глобализующегося мира, требующего разумных обоснований». Фундаментализм не имеет ничего общего с контекстом убеждений, религиозных или атеистических. Главное здесь «то, каким образом истинность этих убеждений отстаивается и утверждается» $[14$, с. 65,66$]$. Фундаментализм категоричен и непримирим, «это отказ от диалога в мире, где спокойствие и будущее именно от диалога и зависят. Фундаментализм - дитя глобализации. Он одновременно является реакцией на нее и методом ее эксплуатации» [15, с. 66]. В отличие от демократического диалога, логики убеждения и взаимоуважения, фундаментализм - требование категорического следования ритуальной традиции, обеспечиваемое нетерпимостью и насилием по отношению к любому от нее отступлению.

Фундаментализм часто маскируется под традиционализм, под которым понимается опора на выраженную в традиции историческую мудрость и опыт. Традиционализм предполагает осмысление нового через призму сложившихся традиций, он открыт к социальным новациям, облекая их в традиционные фрормы, выражает готовность разделять свои традиции с партнерами и уважать традиции других. Традиционализм характерен для стран с азиатской культурой. Особое, восточно-традиционалистское, понятие традиционалистического ритуала можно встретить в трудах Конфуция, который рассматривал его как способ общения с расчетом на взаимность. Ритуал у Конфуция - культурная традиция - средство профилактики разного рода коллизий и осложнений в общении, чья функция была средством адаптации к «внешней среде» на личностном и социальном уровнях. Конфуцианский традиционный ритуал - способ выстраивания позитивных отношений, адаптации к новому и общения с внешним миром [16].

Грань между традиционализмом и фундаментализмом в категоричности, непримиримости и враждебности последнего к иным традициям и новым практикам.

Исторически ритуализация власти как подмена ее эффективности четко проявлялась при распаде империй. В период раннего Средневековья, после краха Римской империи, само существование государств в глобализованном европейском обществе поддерживалось исключительно за счет коллективных ритуалов. Власть суверенов на том этапе не была четко оформлена ни законодательно, ни территориально. Единственным ее проявлением было право на совершение публичных ритуалов, которые и воспринимались обществом как проявление власти, в то время как реальное регулирование общественных отношений осуществлялось на местах, на уровне самоорганизации профессиональных сообществ (гильдий, палат), а также семейно-традиционным и общинным способом. «В средневековом обществе власть дисперсна: она актуализируется и ощущается подвластными непосредственно отнюдь не часто. Например, герцоги и графы, фрактические хозяева обширных территорий и обладатели большой власти, собирались по большим церковным праздникам к королевскому двору. И именно при таких встречах подданные могли увидеть, притом многие впервые, как “выглядит" их королевство: оно не абстрактно, а персонифицировано и предстает взорам как совокупность людей, которые обладают определенным статусом, находящим внешнее выражение в облачениях, знаках власти, пространственном расположении тех или иных фигур и т. п. Королевство тем самым “прочитывалось" присутствовавшими в ходе определенного ритуала, разворачивавшегося у них на глазах», - говорит историк М. Бойцов в статье «Ритуалы - это и есть власть» [17].

Феномен «ритуального» государства в данный период был характерен и для «наследника» Рима - Византии, теряющей экономическое и политическое влияние, замещаемое бюрократизацией и ритуализацией государственных функций, о чем красноречиво повествует византийская 
книга «О церемониях византийского двора», составленная для императора Константина VII Багрянородного (913-959 гг. н. э.), которая «подробнейшим образом описывает придворные ритуалы, часто с поминутной детализацией, с точки зрения распорядителей двора, описывая, как они должны проводить их, бывшая пособием, содержащим консультации и указания для византийских чиновников и придворных» [18]. В условиях упадка Византии это было замещение государственной деятельности бюрократическими ритуалами. Для Европы это был постимперский период, когда государствам нового типа еще только предстояло организоваться.

Характерная ритуализация прослеживалась и в позднем императорском Риме, в «эпоху бездарных цезарей», безуспешно подражавших Юлию и Августу, опиравшихся не на волю и мнение общества, а на ффундаментализм, террор и бесконечные ритуалы.

По мнению социологов, ритуал в современном понимании представляет собой «выработанный обычаем или установлением порядок совершения чего-либо, церемониал» [19, с. 5]. Ритуалы, согласно исследованиям фрранцузского социолога Э. Дюркгейма, характеризуются коллективизмом их исполнения и направлены на выделение и сплочение группы их участников. Так, «следствием постоянного и систематического исполнения ритуалов становится постепенная выработка социальной категории причинности, отличающейся от природной (естественно-научной) причинности; различие в том, что в случае ритуала не виден результат изменения» [20, с. 9]. Э. Дюркгейм выделяет следующие основные виды ритуалов по направленности: отрицательные, представляющие собой систему запретов, и положительные, цель которых - приблизить человека к миру священного. По типу совершаемых действий он выделял ритуалы имитационные - инсценировочные действия и коммеморативные, воспроизводящие события почитаемого прошлого [21, с. 12].

Таким образом, в общих чертах ритуализацию сознания можно охарактеризовать как сознательный коллективный уход от реальности, где процесс воздействия на изменяющуюся социальную среду подменяется формальными действами, эффективность которых не является значимым критерием для их участников. Единственным результатом, с точки зрения участников ритуалов, выступают сплочение их группы и групповой отказ от осознанного взаимодействия с реальностью. Это тот самый случай, когда для участников важен не результат, а процесс.

Характерной и многообъясняющей чертой ритуализации является выделение из социальной группы участников ритуалов особых лидеров-жрецов, на долю которых выпадает роль «хранителей традиций, толкователей, имеющих светскую и духовную власть» [22, с. 65]. Следовательно, сколько бы ни было игроков в ритуале, выигрывает тот, кто им руководит. По мере развития общественных ритуалов число «жрецов» и «служителей» - бюрократов - резко возрастает, формируются их общественные слои. Бюрократизация как фрорма ритуализации на протяжении своей истории - верный спутник деградации государств, противопоставить которому можно централизацию полномочий на наднациональном уровне или возврат их зрелому гражданскому обществу, что и предполагают процессы глобализации. Собственно бюрократия - это и есть псевдоуправленческий ритуал. Исходя из этого, дебюрократизация - это и есть деритуализация.

Подобным образом ритуализация государственных функций влияет и на правотворчество, формируя ритуальное право наподобие поздневизантийского, когда органами власти издаются множественные законодательные и иные нормативные акты, направленные не на фактическое регулирование общественных отношений, а на бесконечную регламентацию действий чиновничьего аппарата, выстраивание его иерархии, установление всякого рода празднований, почитаний или запретов. При принятии данных норм не производится необходимая оценка их реального регулирующего воздействия на актуальные правоотношения в обществе, критерии и обязательность которой хорошо было бы закрепить в международно-правовых нормах.

Глобализация, в свою очередь, требует освобождения от ритуалов, различных для каждого из обществ и государств, высвобождения, очищения от ритуальной маскировки смысла целей и понятий, однородных и общих для всего человечества.

Существенными особенностями ритуализированного сознания являются подчеркнутая отчужденность от фактов реальности и непримиримая враждебность ко всему, что не согласуется с ритуальной логикой, задаваемой организаторами ритуалов. Эти обстоятельства делают ритуализацию общественного сознания первейшим орудием фундаментализма в деле манипуляции обществом.

Благодаря ритуализации общественного сознания происходит отказ от описанного М. Вебером модернистского научного «расколдовывания» (демистификации, интеллектуализации) действительности, шедшего со времен Античности [23], и вновь возникает новая «непрозрачность», мистификация сознания, погружающая современное общество в постмодерн.

Описывая эту загадку, Ю. Хабермас в работе «Философрский дискурс о модерне» не без основания называет модернизм «незавершенным проектом XX столетия», удивляясь его вне- 
запно прерванному полету [24, с. 7]. Отечественная наука вслед за русским мыслителем А. Панариным искала объяснение современному постмодернизму в процессах глобализации и «утрате национальной идентичности атомизируемым обществом» [25, с. 91].

В свете изложенного есть основания предполагать, что истоки современного постмодернизма, точнее сказать отступления от модерна, кроются именно в феномене «ритуального» государства, базирующегося на фундаменталистских идеях и мистификациях, заслоняющих от личности реальность и ее перспективы. Характерной чертой постмодерна «ритуального» государства является отказ от будущего, коллективная ритуальная коммеморация взамен идей о едином прогрессивном будущем. Глобализация, напротив, рассматривается идеологами модерна как средство для созидания общего будущего человечества.

В процессе ритуализации общественного сознания и формирования «ритуального» государства нелегкой выглядит участь церкви и религии, испытывающих серьезное давление со стороны политиков и органов управления, которые неизбежно пытаются подменить их собой (или поглотить, «огосударствить»), вернее, вытеснить подлинные Веру и Религию, подменив их псевдодуховной официальной идеологией. В этом духовном суррогате, эрзаце религии предметом поклонения становятся «гуру» и «жрецы», а предметом исповедания - государственная идеология. Духовная открытость подлинной Веры заменяется на оскалившуюся замкнутость тоталитарной секты. Ярким примером этого могут служить те же «бездарные цезари» позднего императорского Рима, провозглашавшие самих себя богами, ослабление и раздробление церкви в поздний период средневековой Европы, гонения на верующих в революционной России, квазиязычество национал-социалистов гитлеровской Германии.

В конституциях и законодательстве многих стран присутствуют нормы, направленные на гарантии светского характера государства, но сегодня необходимы и международно-правовые гарантии для религиозных организаций от давления и присвоения их функций самим государством, что можно назвать огосударствлением церкви.

Так, христианской церковью Европы пройден «крестный» путь от источника праведной власти, который наделял полновластием над народами по праву «наместника Сына Бога, Иисуса Христа» (Vicarius Filii Dei, Vicarius Christi) средневековых правителей - суверенов, до фрактического инструмента госпропаганды в нацистской Германии и насильственно отстраненного от управления обществом института в современной Европе.

Отказ от фундаментализма, «ритуального» государства и навязываемой идеологии является залогом возврата общества к истинной Вере, подлинного возвращения обществу религиозной духовности.

Пагубную роль в ритуализации общественного сознания играют массмедиа, которые тоже подвержены процессам глобализации. Немецкий исследователь Н. Луман описывает это так: «Глобализация системы медиа ведет к всеохватному характеру распространения информации: масштаб и быстрота сообщения приводят к созданию ощущения, что буквально в следующую секунду она уже известна всем» [26, с. 29]. Основной характеристикой вещательных СМИ является однонаправленный - от источника к получателю, линейный характер процесса передачи информации, в отличие от социальных сетей, без возможности отклика и общественного обсуждения. Таким образом, группы влияния («жрецы») используют вещательные СМИ для вовлечения в ритуалы масс потребителей их контента, превращая саму передачу и коллективное одностороннее восприятие (зачастую некритическое) данного контента в «медиаритуал».

Поскольку общественный контроль за медиагигантами весьма сложен и дорог для общества, нужно законодательно ограничивать их влияние на аудиторию путем демонополизации и либерализации медиапространства, введения квот на вещание на международном законодательном уровне. Сегодня остро стоит проблема злоупотреблений в информационной сфере интернет-гигантов, бесконтрольно собирающих и использующих данные граждан и компаний в интересах национальных правительств и международного бизнеса. Правовое регулирование данных вопросов возможно исключительно на международном уровне.

Фундаментализм использует ритуализацию, «заколдовывание» реальности при помощи «медиаритуалов» как эрзац-религию для растерянных умов, столкнувшихся со сложностями глобализующегося мира, отгораживая их от реальности, погружая в «омут» постмодернизма, заслоняя от них подлинную действительность и истинную духовность.

Парадокс заключается в том, что фундаментализм, как и все иное, активно использует плоды глобальных информационных технологий, словами Э. Гидденса: «одновременно является реакцией на нее <глобализацию> и методом ее эксплуатации, благодаря современным технологиям, мировым СМИ, обретает мировой, глобальный масштаб» [27, с. 66]. Этим объясняется непримиримая атака фундаменталистов всех мастей на право граждан участвовать в свободном глобальном информационном диалоге в сети. 
Именно с развитием Интернета и социальных сетей как глобальной дискуссионной среды, площадки подлинной народной дипломатии, саморегулируемой на основе принципов демократии и толерантности системы, связан новый, народный, тип глобализации, направленный на формирование независимых наднациональных объединений, саморегулируемых общественных структур единого постполитического мира. Это и есть подлинное возрождение модерна в его глобальном мировом масштабе, глобальная революция.

На противоположном полюсе этих процессов находится иной тип глобализации, когда крупные национальные или интернациональные группы борются за расширение влияния путем ритуализации общества, отчуждения его от реальности, навязывания ему идеологии фрундаментализма или изоляционизма. Это путь усиления политической борьбы, невозможной без разрушения, подавления и насилия. Именно с ним связаны крен общества к бездуховности, современному постмодерну, отказу от идеи покорения будущего, погружение в пучину современной магии, эрзац-религии, медиаритуалов и бюрократического произвола.

Надежда, как всегда, устремлена в будущее, к тем, кому оно по праву принадлежит, - к молодежи, которая подсознательно выбирает демократичные формы глобализации, активно используя возможности Интернета, участвует в глобальной революции, изменяющей личность и общество на современном этапе. Тогда как в ловушки фундаментализма и изоляционизма «ритуального» государства попадают люди старших поколений, очарованные СМИ и не сумевшие освоить новые технологии информационного обмена.

Таким образом, залогом формирования нового наднационального постполитического будущего является единая и свободная информационно-коммуникационная среда, основанная на доступе к сети Интернет. Создаваемый в рамках данной среды свободный информационный обмен и коммуникация способствуют развитию гражданского общества и демократии, торжеству справедливости, укрепляют мир между народами.

Несмотря на экспоненциальный рост данных процессов, права их участников на свободный доступ к информационно-коммуникационной среде, на объединение усилий на наднациональном уровне требуют международных гарантий и законодательных механизмов защиты от глобальных информационных манипуляций и ритуализации сознания, насаждаемых преследующими корыстные цели международными группами влияния, фундаменталистами и «захваченными» ими «ритуальными» государствами.

Следствием отказа общества от псевдоуправленческих ритуалов станет не только крах фундаментализма и бюрократии, но и выработка, очищение единых глобальных смыслов, которые будет использовать человечество при глобальном взаимодействии, в том числе с участием искусственного интеллекта.

Залогом формирования единого постполитического будущего, подлинной народной глобализации, возвращения к проекту модерна и истинным духовным ценностям на новом наднациональном уровне являются защита прав человека на свободный доступ и обмен инфрормацией, запрет на подмену религиозной морали и духовности порождаемыми бюрократией и группами влияния идеологическими эрзацами. Ведущая роль в этом процессе должна принадлежать международному и, в идеале, мировому (глобальному) праву, нормам, принимаемым всеми в разрезе каждого.

Таким образом, на современном этапе необходимы срочная разработка и принятие норм международного права: о дополнении европейской Конвенции о защите прав человека и основных свобод положениями о гарантиях естественного права человека на свободный доступ к сети Интернет и обмен информацией в ней; о международной конвенции о правах и статусе наднациональных объединений активистов; о международном кодексе об обмене и использовании информации (информационном кодексе); о единых механизмах защиты прав человека на свободный обмен информацией от незаконного ограничения государственными органами (международном суде по защите прав в сфрере информационного обмена).

\section{Ссылки:}

1. Изместьев С.В. Кризис государства как социально-политического института в эпоху глобализации // Теория и практика общественного развития. 2020. № 7. С. 63-72. https://doi.org/10.24158/tipor.2020.7.11.

2. Гидденс Э., Саттон Ф. Основные понятия в социологии / пер. с англ. Е. Рождественской, С. Гавриленко. М., 2018. 336 с.

3. Гидденс Э. Ускользающий мир: как глобализация меняет нашу жизнь / пер. с англ. М.Л. Коробочкина. М., 2004. 120 с.

4. Там же. С. 92.

5. Там же. С. 86

6. Там же. С. 92

7. Finland Makes Broadband a 'Legal Right' [Электронный pecypc] // BBC News. 2010. July 1. URL: https://www.bbc.com/news/10461048 (дата обращения: 27.08.2020). 
8. Report of the Special Rapporteur on the Promotion and Protection of the Right to Freedom of Opinion and Expression [Электронный ресурc] : Report no. A/HRC/17/27 // United Nations General Assembly. URL: https://www2.ohchr.org/english/bodies/hrcouncil/docs/17session/A.HRC.17.27_en.pdf (дата обращения: 27.08.2020).

9. Благовещенский А. ООН признала право на доступ в Интернет неотъемлемым [Электронный ресурс] // Российская газета. 2011. 7 июня. URL: https://rg.ru/2011/06/07/oon-site-anons.html (дата обращения: 27.08.2020).

10. Скобелев В. Прирост интернет-аудитории в 2019 г. обеспечили пенсионеры [Электронный ресурс] // РБК. 2020. 13 янв. URL: https://www.rbc.ru/technology_and_media/13/01/2020/5e1876549a7947210b5ef636 (дата обращения: 27.08.2020)

11. Freedom on the Net 2019. The Crisis of Social Media [Электронный ресурс] // Freedom House. 2019. URL: https://freedomhouse.org/sites/default/files/2019-11/11042019_Report_FH_FOTN_2019_final_Public_Download.pdf (дата обращения: 27.08.2020)

12. Шлык Р.Ю. Изоляционизм // Новая философская энциклопедия / под ред. В.С. Стёпина. В 4 т. М., 2000-2001. Т. 2.

13. Гидденс Э. Указ. соч. С. 87.

14. Там же. С. $65,66$.

15. Там же. С. 66.

16. Лапина 3.Г. Доктрина государства в контексте востоковедения как система средств гармонизации социума (на примере традиционного Китая) // Общество и государство в Китае. 2014. Т. 44, № 1. С. 51-56.

17. Ритуалы - это и есть власть. Интервью с историком Михаилом Бойцовым об обряде средневековой коронации, практике помазания и статусе королевской власти в Европе [Электронный ресурс] // ПостНаука : издательский дом. 2014. 7 нояб. URL: https://postnauka.ru/talks/35978 (дата обращения: 27.08.2020).

18. Тафт Р.Ф. Византийский церковный обряд / пер. с англ. А.А. Чекаловой. СПб., 2000. 158 с.

19. Черных А.И. Ритуалы в медиатизированном обществе : препринт. М., 2012. 56 с.

20. Там же. С. 9.

21. Там же. С. 12.

22. Гидденс Э. Указ. соч. С. 65.

23. Вебер М. Социология религии : монография. М., 2010. 561 с.

24. Хабермас Ю. Философский дискурс о модерне : пер. с нем. М., 2003. 416 с.

25. Панарин А.С. Искушение глобализмом. М., 2003. 384 с.

26. Черных А.И. Указ. соч. С. 29.

27. Гидденс Э. Указ. соч. С. 66. 